IZA DP No. 9147

Innovation and Employment in Patenting Firms:

Empirical Evidence from Europe

Vincent Van Roy

Daniel Vertesy

Marco Vivarelli

June 2015 


\title{
Innovation and Employment in Patenting Firms: Empirical Evidence from Europe
}

\author{
Vincent Van Roy \\ European Commission, Joint Research Centre \\ Daniel Vertesy \\ European Commission, Joint Research Centre
}

Marco Vivarelli

Università Cattolica del Sacro Cuore, SPRU, University of Sussex and IZA

\author{
Discussion Paper No. 9147 \\ June 2015
}

\author{
IZA \\ P.O. Box 7240 \\ 53072 Bonn \\ Germany \\ Phone: +49-228-3894-0 \\ Fax: +49-228-3894-180 \\ E-mail: iza@iza.org
}

\begin{abstract}
Any opinions expressed here are those of the author(s) and not those of IZA. Research published in this series may include views on policy, but the institute itself takes no institutional policy positions. The IZA research network is committed to the IZA Guiding Principles of Research Integrity.

The Institute for the Study of Labor (IZA) in Bonn is a local and virtual international research center and a place of communication between science, politics and business. IZA is an independent nonprofit organization supported by Deutsche Post Foundation. The center is associated with the University of Bonn and offers a stimulating research environment through its international network, workshops and conferences, data service, project support, research visits and doctoral program. IZA engages in (i) original and internationally competitive research in all fields of labor economics, (ii) development of policy concepts, and (iii) dissemination of research results and concepts to the interested public.
\end{abstract}

IZA Discussion Papers often represent preliminary work and are circulated to encourage discussion. Citation of such a paper should account for its provisional character. A revised version may be available directly from the author. 


\section{ABSTRACT}

\section{Innovation and Employment in Patenting Firms: Empirical Evidence from Europe}

This paper explores the possible job creation effect of innovation activity. We analyze a unique panel dataset covering almost 20,000 patenting firms from Europe over the period 2003-2012. The main outcome from the proposed GMM-SYS estimations is the labourfriendly nature of innovation, which we measure in terms of forward-citation weighted patents. However, this positive impact of innovation is statistically significant only for firms in the hightech manufacturing sectors, while not significant in low-tech manufacturing and services.

JEL Classification: $\quad 031,033$

Keywords: technological change, innovation, patents, employment, GMM-SYS

Corresponding author:

Marco Vivarelli

Università Cattolica del Sacro Cuore

Istituto di Politica Economica

Largo Gemelli 1

I-20123 Milano

Italy

E-mail: marco.vivarelli@unicatt.it

\footnotetext{
* This research was funded by the Innova Measure project by the Directorate-General of Research and Innovation of the European Commission (DG RTD). The authors are grateful to Nathan Wajsman and Michal Kazimierczak from the Office for Harmonization in the Internal Market (OHIM) for providing access to the EPO/OHIM concordance tables, and to Mariacristina Piva and Dieter Somers for useful suggestions.
} 


\section{Introduction}

The century-old debate on the effect of innovation on employment has once again rose to prominence in light of the recent financial crisis and the subsequent slow recovery, triggering intense debates and capturing news headlines (Brynjolfsson and McAfee, 2011, 2014). Indeed, the diffusion of the ICT-based technologies created new markets and job opportunities, but rendered some skills and traditional jobs obsolete. International organizations, including the ILO, UNIDO, IDB and the OECD are increasingly concerned with the issue of avoiding jobless growth as countries recover from the crisis (see, for instance, Crespi and Tacsir, 2012; UNIDO, 2013). In this context, the European Commission formulated its 'Europe 2020' strategy in 2010 with the aim to create the conditions for a smart, sustainable and inclusive growth (European Commission, 2010), a particularly relevant agenda for a stagnating Europe that faces growing social tensions (Fagerberg et al., 2015, forthcoming).

At the heart of the controversy, we find the clash of two views. One states that laborsaving innovations create technological unemployment, as a direct effect. The other view argues that product innovations and indirect (income and price) effects can counterbalance the direct effect of job destruction brought about by the process innovations incorporated in new machineries and equipment (for fully articulated analytical discussions, see Petit, 1995; Spiezia and Vivarelli, 2002; Pianta, 2005; Vivarelli, 2013, 2014).

In particular, the so-called "compensation theory" - which traces back its origins to classical economists such as Say (1964) Ricardo (1951) and Marx (1961) - puts forward the view that process innovations lead to more efficient production and thus, assuming competitive markets, increasing demand and hence employment (for modelling based on this approach, see Neary, 1981; Sinclair, 1981; Waterson and Stoneman, 1985). Alternatively - in case of imperfect competition where prices decline with some attrition and lags - innovative firms distribute the benefits associated with the new technologies in the form of extra profits and wages. In turn, these additional incomes can create jobs either through increased investment, or through increased demand due to higher consumption expenditures (see Pasinetti, 1981; Boyer, 1988; Vivarelli, 1995). However, these compensation mechanisms can be seriously dampened in case of monopolistic markets where prices do not decrease due to lack of competition, in case the demand elasticity is low, or when investment and consumption decisions are limited by different factors such as pessimistic expectations or 
credit rationing (for analyses focusing on these critical aspects, see Freeman and Soete, 1987; Vivarelli, 1995; Pianta, 2005; Vivarelli, 2014).

While these controversies center on the overall employment effect of process innovations, there is less debate about the positive employment effect of product innovations. These are generally understood to lead to the opening of new markets, or to an increased variety within the existing ones (see Katsoulacos, 1984; Freeman and Soete, 1987; Vivarelli, 1995; Edquist et al., 2001; Antonucci and Pianta, 2002; Bogliacino and Pianta, 2010).

However, even the labor-friendly impact of product innovation may be more or less powerful. Indeed, the so-called "welfare effect" (the creation of new goods) should be compared with the "substitution effect" (that is the displacement of mature products by the new ones: think, for instance, to smartphones replacing cameras, music players and fax machines; see Katsoulacos, 1984, 1986).

As it should be clear even from the brief summary discussed above, theoretical models cannot claim to have a clear answer in terms of the final employment impact of process and product innovation. Indeed, price and income mechanisms do have the possibility to compensate the direct labor-saving effect of process innovation, but their actual effectiveness is unsteady and depends on key parameters such as the degree of competition, the demand elasticity, the consumers' and entrepreneurs' expectations. On the one hand, depending on the different institutional and economic contexts, compensation can be more or less effective and technological unemployment only partially reabsorbed (Feldmann, 2013). On the other hand, labor-friendly product innovation may overcome the possible labor displacement brought about by process innovation and so foster job creation.

Since economic theory does not have a clear-cut answer about the employment effect of innovation, there is a strong need for empirical analyses able to test the final employment impact of technological change. In particular, a recent strand of literature - based on microeconometric studies - has the great advantage to allow a direct and precise firm-level mapping of innovation variables and their effect on employment.

This paper aims to provide further and novel empirical evidence within this strand of literature (surveyed in Section 2). In more detail, we use a unique longitudinal database of approximately 20,000 patenting firms from 22 European countries, over the period 20032012, and we test the possible job creation impact of innovation activity.

This paper differs from prior work from different perspectives. Firstly, we measure the impact of innovation from a "quality" perspective; for this purpose, we rely on forwardcitation weighted patent counts that reflect the technological importance of patents for the 
development of subsequent technologies ${ }^{1}$ (see Trajtenberg, 1990; Harhoff et al., 2003; Hall et al., 2005). Secondly, we contribute to the existing literature by analyzing the effects of innovation on labor demand using a large EU wide panel dataset, while most of previous studies rely on single country databases. Thirdly, we present evidence for separately manufacturing and services and for high-tech versus low-tech manufacturing sectors and so we are able to disentangle the emergence (or the absence) of job-creating effects across the different economic sectors.

The rest of the paper is organized as follows: Section 2 provides an overview of previous empirical literature on the relationship between innovation and employment at the firm level; Section 3 presents the dataset and the variables; Sections 4 and 5 describe the econometric model and discuss the results. We conclude in Section 6, also providing some policy implications.

\section{Previous empirical literature}

Starting in the '90s, there has been a growing literature investigating the link between technological change and employment at the micro level. Early studies, although interesting, were based on cross-section analyses, unable to control for firms' unobserved heterogeneity and affected by (possibly serious) endogeneity problems.

For instance, Entorf and Pohlmeier (1990) found a positive impact on employment of product innovation, measured using a dummy, in a cross-section of 2,276 West German firms in 1984. Other authors found no significant link or outright negative impact of new technology on jobs. For example, Zimmermann (1991) found that technological change contributed to employment decrease in 16 German industries over the 1980s. By the same token, Brouwer et al. (1993) found a negative relationship between aggregate $R \& D$ expenditures and employment (but a positive relationship when only product innovations were considered) in a cross-sectional study of 859 Dutch manufacturing firms. Finally, Klette and Førre (1998) examined 4,333 Norwegian manufacturing firms over the period 1982-1992 and found no significant relationship between R\&D intensity and net job creation.

More recent studies have fully taken the advantage of new available longitudinal datasets and have applied panel data econometric methodologies that jointly take into account

\footnotetext{
${ }^{1}$ In so doing, we depart from previous literature that either rely on measures of innovative inputs (typically R\&D) or on dummies for innovative output (such as product and/or process innovation as declared in the Community Innovation Surveys); see Section 2.
} 
time dimension and individual variability and so can effectively deal with the unobserved heterogeneity and the endogeneity issues recalled above.

For example, Van Reenen (1997) matched the London Stock Exchange database of manufacturing firms with the SPRU (Science Policy Research Unit at the University of Sussex) innovation database and obtained a panel of 598 British firms over the period 19761982. The author found a positive employment impact of innovation and this result turned out to be robust after controlling for fixed effects, dynamics and endogeneity.

An interesting result was obtained by Greenan and Guellec (2000), using a panel of microdata from 15,186 French manufacturing firms over the 1986-1990 period. According to the authors, innovating firms create more jobs than non-innovating ones, but this outcome is reversed when moving to the sectoral level, where the overall effect is negative and only product innovations reveal to be job-creating. A possible explanation of this reverse in the employment outcome is the so-called 'business stealing effect': at the level of the individual firms, innovators tend to perform better in terms of employment as they gain market share at the expenses of laggards and non-innovators. Even when innovation is intrinsically laborsaving, correlations at the micro-level generally show a positive link between technology and employment, since they do not take into account the crowding-out effect on non-innovators; however, a negative overall effect may emerge at the sectoral or more aggregate levels.

However, even controlling for the business stealing effect (by a demand variable such as sales), Piva and Vivarelli $(2004,2005)$ found evidence in favor of a positive effect of innovation on employment at the firm level. The authors applied the GMM-SYS methodology to a longitudinal dataset of 575 Italian manufacturing firms over the period 1992-1997, and found a significant positive link between innovative investment and employment, although small in magnitude.

A number of even more recent studies further explored the displacement or compensation mechanisms due to different types of innovation. Based on Peters (2004), Harrison et al. (2008, 2014) - using the 3rd Community Innovation Surveys (CIS) from France, Germany, UK and Spain - concluded (in accordance with the theoretical literature, see Section 1) that process innovation tends to displace employment, while product innovation is basically labor friendly. Compensation mechanisms were found to be particularly effective in the service sectors through increased demand for new products (see also Evangelista and Savona, 2003; Evangelista and Vezzani, 2012). 
Using a similar model, Hall et al. (2008) found a positive effect on employment of product innovation and no evidence of employment displacement due to process innovation using a panel of Italian manufacturing firms over the period 1995-2003.

Interestingly, Lachenmaier and Rottmann (2011) are somewhat in contrast with the former findings. The authors applied a dynamic employment equation (GMM-SYS) on a very comprehensive dataset of German manufacturing firms over the period 1982-2002, including wages, gross value added, year and industry controls, and alternative proxies (dummies) of current and lagged product and process innovation. Their estimates show a positive, significant impact of different innovation measures on employment, with the positive impact of process innovations even higher than that of product innovations.

Since in this contribution we will split our micro analysis according to sectoral belonging, it is useful to look at prior literature to investigate whether some previous studies have singled out sectoral specificities in the relationship between innovation and employment.

Indeed, a handful of studies found important differences in the employment job creation effect of innovation across different industry groups. For instance, Greenhalgh et al. (2001) explored a panel of UK firms over the period 1987-1994 and their fixed effects aggregate estimates showed a modest, but positive impact of $R \& D$ expenditures on employment. However, once splitting the panel into high- and low-tech sectoral groups, the positive impact of R\&D on employment turned out to be limited to high-tech sectors.

Consistently, Buerger et al. (2010) - using data concerning four manufacturing sectors across German regions over the period 1999-2005 - have studied the co-evolution of R\&D expenditures, patents and employment through a VAR methodology. Their main result is that patents and employment turned out to be positively and significantly correlated in two hightech sectors (medical and optical equipment and electrics and electronics), while not significant in the other two more traditional sectors (chemicals and transport equipment).

A positive relationship between innovation and jobs is also found by Coad and Rao (2011) who limit their focus on U.S. high-tech manufacturing industries over the period 1963-2002 and investigate the impact of a composite innovativeness index (comprising information on both R\&D and patents) on employment. The main outcome of their quantile regressions is that innovation and employment are positively linked, and that innovation has a stronger impact for those firms that reveal the fastest employment growth.

By the same token, Bogliacino et al. (2012) - using a panel database covering 677 European manufacturing and service firms over 19 years (1990-2008) - found that a positive 
and significant employment impact of $R \& D$ expenditures is clearly detectable only in services and high-tech manufacturing but not in the more traditional manufacturing sectors, where the employment effect of technological change is not significant (see also Bogliacino and Vivarelli, 2012).

On the whole, recent microeconometric studies offer a detailed mapping of the jobcreating impact of innovation which generally turns out to overcome its possible job displacement effects. However, the (few) studies investigating the sectoral dimension reveal that this labor-friendly impact is generally limited to the high-tech sectors, characterized by an higher R\&D intensity and by the prevalence of product innovation.

\section{Data and variables}

\subsection{Data}

Our original dataset is based on a panel of European patenting firms. ${ }^{2}$ We make use of a joint statistical effort made by the European Patent Office (EPO) and the Office for Harmonization in the Internal Market (OHIM). In particular, we matched accounting company data originating from ORBIS $^{3}$ with patent and patent quality information from the OECD PATSTAT dataset using firm-patent concordance tables developed by EPO and OHIM (EPO and OHIM, 2013). This allowed us to assign a quality measure - based on forward citations to patents and to control for differences across patent classes.

The matched dataset covers 63,561 EU-based, patenting firms from 27 EU Member States for the years 2003-2012 and belonging to manufacturing and service sectors. This unique database provides information on firms' legal aspects and location, industrial activity (NACE sector) and fundamental economic information (including employment, sales, value added, capital formation, and cost of labor).

We then cleaned our dataset following a methodology similar to that applied by Hall and Mairesse (1995); in particular: (1) we excluded firms for which either sectoral belonging, employment, value added, fixed assets or cost of labor were missing or not positive; (2) we

\footnotetext{
${ }^{2}$ In this study, we consider only firms identified by the EPO/OHIM study (2013) as having filed at least one patent over the period 2004-2008.

${ }^{3}$ ORBIS is a commercial database of Bureau van Dijk which provides legal and financial information on European-based companies. Data originates from company reports collected by different providers specific to each country.
} 
dropped outliers in both levels and growth rates. ${ }^{4}$ A more detailed discussion of the data sources and the cleaning process can be found in the Appendix 1. Here it is enough to notice that the economic data provided by ORBIS are rather patchy and their quality is heterogeneous across countries. Across the $27 \mathrm{EU}$ countries, almost $60 \%$ of firms were dropped in what was described above as step (1), and about 4\% in step (2). As a consequence, countries with relatively better data quality and a larger number of available observations mostly Italy - are overrepresented in the cleaned sample, while others - most notably Germany and the UK - are underrepresented. ${ }^{5}$

Eventually, our final sample comprises 23,111 firms, further reduced to 19,978 companies (resulting into 104,074 observations) for computational reasons concerning our estimation procedure (see Section 4).

\subsection{Variables and descriptive statistics}

Our dependent variable is denoted by the natural logarithm of the number of employees within the firm. Explanatory variables of the models are derived from a standard labor demand function (see Section 4) and include firm output, gross investment and labor cost. In particular, we measure firm output through the natural logarithm of value added and gross investment through the annual rate of growth in fixed assets; finally, labor cost is measured as the natural logarithm of the gross wage per employee. Value added, fixed capital investment and labor cost were deflated using industry-specific deflators. ${ }^{6}$ While we expect a negative impact of the labor cost on labor demand, the other two variables are expected to contribute with a positive sign.

Prior studies assessed the impact of innovation on labor demand by using input measures of innovation such as $R \& D$ expenditures, or discrete output measures such as innovation dummies (see Section 2). However, these indicators are not without drawbacks; indeed, the link between $R \& D$ expenditures and successful innovative outcomes involves lags and uncertainty (Nelson and Winter, 1982; Dosi, 1988; Dosi and Nelson, 2013), while innovation dummies do not capture differences of magnitude and quality in innovation outcomes.

\footnotetext{
${ }^{4}$ This was carried out by allocating firms to four groups based on size in which we allowed smaller firms to grow more than larger ones (see Appendix 1).

${ }^{5}$ At least part of this country unbalances can be attributed to the fact that companies below a certain threshold in terms of employment and value added are allowed to file abbreviated financial accounts in many countries in our sample.

${ }^{6}$ In more detail, financial information provided in current prices in the ORBIS database were converted into constant prices by using sectoral GDP deflators (source: Eurostat National Accounts) centered on the year 2005.
} 
To overcome these disadvantages, we use the natural logarithm of citation-weighted patents in our model. Indeed, the selected key impact variable is characterized by some advantages and some limitations. As far as the formers are concerned, it is an indicator of innovative output representing a successful innovation introduced into the market and actually affecting firm's economic performance and its employment. Moreover, as mentioned above, it is a weighted variable, taking into account the quality of the introduced innovation in terms of its technological novelty and therefore its economic impact (see Trajtenberg, 1990; Harhoff et al., 2003; Hall et al., 2005). ${ }^{7}$ On the other hand, patents better proxy product innovation rather than process innovation for which other appropriability instruments are preferred (see Levin et al., 1987). Indeed, while new products are patented to prevent imitation and reverse engineering, process innovation are often embodied in new machineries provided by supplier companies, can be kept secret more easily and therefore are more rarely patented, so accounting for only about 20/30\% of total patents (see Arundel and Kabla, 1998). Since product innovations tend to be more labor-friendly than process innovation (see Sections 1 and 2), this bias in our key impact variable will have to be taken into account in interpreting our results (see Section 6).

The patent quality indicator we use for the regression estimations is denoted as follows:

Weighted patents $i, t=\sum_{p=1 \in i, t}^{n} \frac{1+\text { Forward citations } p, t, f_{\text {Max. Forward citations } t, f}}{\text { Mart }}$

This indicator is obtained by augmenting a simple patent count by the number of subsequent citations that a patent $p$ receives, with forward citations counted over a period of three years after the patent's publication date. ${ }^{8}$ The weighted patent indicator is normalized by technology field $f$ and filing year $t$ in order to account for the differences in citation patterns across technology fields and over time (i.e. we control for the well-known circumstance that patents are more cited in certain technology fields and years, while less in others). This is implemented by dividing the forward citations received from each patent $p$ by the maximum

\footnotetext{
7 The OECD Patent Quality database makes available a Patent Quality Index along with a variety of patent quality indicators which include patent scope, family size, claims, etc (see Squicciarini et al, 2013). However, applying the composite patent quality index (or its components) as our proxy for innovation would significantly reduce our sample size due to the longer citation window applied and to the fact that forward citations is the most widely available indicator among those offered in this database.

8 The percentage of patents from our firm sample that do not get cited in subsequent patents within a 3-year window equals to 75.64 .
} 
number of forward citations in the same technology field and filing year, prior to summing up all patents issued by firm $i$ in the year $t .^{9}$

Finally, we lag our patent indicator by 3 years, to take into account the potential delay in the possible impact of innovation on employment. ${ }^{10}$

In addition to the specifications with the preferred patent quality indicator, as a robustness check we also run the regressions using a simple normalized patent count indicator. ${ }^{11}$

To control for industry, year and country-specific differences in labor demand dynamics, we include 22 industry-, 9 year- and 22 country dummies in the model.

Table 1 reports the summary statistics of the dependent and explanatory variables used in the estimations. Correlations among the variables are presented in the Appendix 2 (Table A2.1).

Table 1: Summary statistics of the dependent and explanatory variables

\begin{tabular}{lrrrrrr}
\hline Variable name & \multicolumn{1}{c}{ Mean } & \multicolumn{1}{c}{ Min. } & \multicolumn{1}{c}{ Max. } & \multicolumn{1}{c}{ SD } & SD between & \multicolumn{1}{c}{ SD within } \\
\hline Employment & 721.13 & 1.00 & $75,197.00$ & $3,425.36$ & $2,825.96$ & 511.40 \\
Value added & $61,632.41$ & 0.00 & $19,296,940.00$ & $376,024.00$ & $310,399.40$ & $80,080.30$ \\
Weighted patents & 0.09 & 0.00 & 83.09 & 0.85 & 0.72 & 0.35 \\
Patents & 0.03 & 0.00 & 21.54 & 0.26 & 0.21 & 0.08 \\
Gross investment & 3.30 & -291.80 & 543.44 & 28.31 & 17.57 & 24.85 \\
Labor cost per employee & 45.25 & 0.06 & 221.05 & 17.45 & 17.11 & 6.63 \\
\hline
\end{tabular}

Notes: $\mathrm{N}=104,074$ observations. Value added and labor costs are expressed in thousands of euros, while gross investments denote percentage growth

Table 2 reveals that our panel database covers the whole range of small-, medium- and largesized enterprises, although it is biased towards the two latter categories (Table 1). This bias stems from the fact that we uses patent information as proxy for the innovative activities of firms, leading to the exclusion of many micro- and small-sized firms after merging the original firm-level ORBIS dataset with the EPO/OHIM database. Indeed, medium- and largesized firms account for roughly 64 percent of the panel when analyzing firm size in the first year of appearance of each firm in the sample (see Table 2).

\footnotetext{
${ }^{9}$ Since many patents do not receive any forward citation (see previous footnote), the numerator is increased by 1 in order to keep these patents.

10 Model estimations have also been run with a 2-year lagged patent indicator and yielded similar results (available upon request).

${ }^{11}$ We divided the firm's patents by the maximum number of patents in the same technology field and year and multiplied by 100 .
} 
Table 2: Distribution of firms across size

\begin{tabular}{lrc}
\hline Firm size & Numbers & \multicolumn{1}{c}{ Perc. } \\
\hline Micro & 2,854 & 14.29 \\
Small & 5,461 & 27.34 \\
Medium & 6,740 & 33.74 \\
Large & 4,923 & 24.64 \\
\hline Total & 19,978 & 100.00 \\
\hline
\end{tabular}

Note: Firm size groups are denoted as: micro: 0-10 employees, small: 11-50 employees, medium: 51-250 employees and large: more than 250 employees

Turning our attention to the distribution of firms across sectors, Table 3 shows that the dataset covers all economic activities. Not surprisingly (given our focus on patenting firms) the most represented sectors within manufacturing are the chemical sector (about 10\%), the metal industry (12\%) and the machinery sector (17\%). Retail trade (11\%) and scientific research providers $(6 \%)$ are the most represented services in the sample. ${ }^{12}$

Table 3: Distribution of firms across sectors

\begin{tabular}{|c|c|c|c|c|}
\hline & \multicolumn{2}{|c|}{ Observations } & \multicolumn{2}{|c|}{ Firms } \\
\hline & Numbers & Perc. & Numbers & Perc. \\
\hline \multicolumn{5}{|l|}{ Manufacturing } \\
\hline Food & 2,539 & 2.44 & 430 & 2.15 \\
\hline Textile & 2,825 & 2.71 & 510 & 2.55 \\
\hline Paper & 3,286 & 3.16 & 587 & 2.94 \\
\hline Chemistry & 11,072 & 10.64 & 1,997 & 10.00 \\
\hline Pharmaceutical & 2,321 & 2.23 & 397 & 1.99 \\
\hline Minerals & 2,639 & 2.54 & 480 & 2.40 \\
\hline Metal & 12,279 & 11.80 & 2,266 & 11.34 \\
\hline Electronics & 10,640 & 10.22 & 2,039 & 10.21 \\
\hline Machinery & 17,460 & 16.78 & 3,212 & 16.08 \\
\hline Transport & 3,954 & 3.80 & 706 & 3.53 \\
\hline Other Manufacturing & 6,531 & 6.28 & 1,217 & 6.09 \\
\hline \multicolumn{5}{|l|}{ Services } \\
\hline Electricity/Water & 1,148 & 1.10 & 208 & 1.04 \\
\hline Retail trade & 11,406 & 10.96 & 2,341 & 11.72 \\
\hline Transport Services & 963 & 0.93 & 172 & 0.86 \\
\hline Hotel \& Catering & 166 & 0.16 & 47 & 0.24 \\
\hline Telecommunication & 2,586 & 2.48 & 587 & 2.94 \\
\hline Finance & 1,061 & 1.02 & 229 & 1.15 \\
\hline Real Estate & 647 & 0.62 & 157 & 0.79 \\
\hline Scientific & 8,408 & 8.08 & 1,909 & 9.56 \\
\hline Administration/Education & 1,388 & 1.33 & 314 & 1.57 \\
\hline Other services & 755 & 0.73 & 173 & 0.87 \\
\hline Total & 104,074 & 100.00 & 19,978 & 100.00 \\
\hline
\end{tabular}

\footnotetext{
12 The number of service firms in the sample is significantly lower than their share in the population of firms across Europe. This is due to the fact that service firms are far less involved in patenting.
} 
Table 4 reports the distribution of the retained firms across the different European countries. Although our original intention was to cover all EU Member States, eventually the cleaned sample provides information for 22 countries, while the remaining are not covered due to incomplete financial information in the ORBIS database and/or missing patent information in the EPO/OHIM database; however, larger Member States are all included and the diversity of European regions is well-represented. Nevertheless, we note that Italy - accounting for about $36 \%$ of the included firms - is over-presented in the sample due to data quality, as discussed above. To account for this potential bias, we provide estimations excluding Italy in the Appendix 2 (Table A2.2); as can be seen, results remain virtually unchanged.

Table 4: Distribution of firms across countries

\begin{tabular}{lrrrr}
\hline & \multicolumn{2}{c}{ Observations } & \multicolumn{2}{c}{ Firms } \\
& Numbers & Perc. & Numbers & \multicolumn{1}{c}{ Perc. } \\
\hline Austria & 1,733 & 1.67 & 520 & 2.60 \\
Belgium & 1,799 & 1.73 & 294 & 1.47 \\
Bulgaria & 39 & 0.04 & 7 & 0.04 \\
Czech Republic & 649 & 0.62 & 116 & 0.58 \\
Denmark & 240 & 0.23 & 29 & 0.15 \\
Finland & 3,389 & 3.26 & 700 & 3.50 \\
France & 12,707 & 12.21 & 2,901 & 14.52 \\
Germany & 23,296 & 22.38 & 4,888 & 24.47 \\
Greece & 69 & 0.07 & 13 & 0.07 \\
Hungary & 104 & 0.10 & 33 & 0.17 \\
Ireland & 144 & 0.14 & 36 & 0.18 \\
Italy & 33,177 & 31.88 & 5,934 & 29.70 \\
Latvia & 9 & 0.01 & 1 & 0.01 \\
Luxembourg & 81 & 0.08 & 27 & 0.14 \\
Poland & 431 & 0.41 & 103 & 0.52 \\
Portugal & 411 & 0.39 & 78 & 0.39 \\
Romania & 143 & 0.14 & 23 & 0.12 \\
Slovakia & 41 & 0.04 & 8 & 0.04 \\
Slovenia & 201 & 0.19 & 41 & 0.21 \\
Spain & 9,249 & 8.89 & 1,400 & 7.01 \\
Sweden & 5,003 & 4.81 & 851 & 4.26 \\
United Kingdom & 11,159 & 10.72 & 1,975 & 9.89 \\
\hline Total & 104,074 & 100.00 & 19,978 & 100.00 \\
\hline
\end{tabular}




\section{The model}

The stochastic version of a standard labor demand augmented by including innovation (see, for similar approaches: Van Reenen, 1997; Lachenmaier and Rottmann, 2011; Bogliacino et al., 2012) for a panel of firms $i$ over time $t$ is:

$l_{i, t}=\alpha y_{i, t}+\beta w_{i, t}+\gamma$ invest $_{i, t}+\delta$ innov $_{i, t-3}+\left(\varepsilon_{i}+v_{i, t}\right) \quad i=1, . ., n ; t=1, \ldots, T$

where small letters denote natural logarithms, $l$ is labour, $y$ output (in our setting proxied by value added), $w$ wages, invest is gross investments, innov denotes - in our setting - either normalized patent counts or citation-weighted patent counts, $\varepsilon$ is the idiosyncratic individual and time-invariant firm's fixed effect and $v$ the usual error term.

In order to take into account viscosity in the labor demand (as common in the literature, see Arellano and Bond, 1991; Van Reenen, 1997), we move from the static expression (2) to the following proper dynamic specification:

$l_{i, t}=\chi l_{i, t-1}+\alpha y_{i, t}+\beta w_{i, t}+\gamma$ invest $_{i, t}+\delta$ innov $_{i, t-3}+\left(\varepsilon_{i}+v_{i, t}\right)$

To solve the obvious endogeneity problem in the model (see Section 2), we estimate equation (3) using the system GMM approach developed by Blundell and Bond (1998). ${ }^{13}$ Hence, estimates are obtained by running a system of equations in first differences and in levels, which are run simultaneously (with the level equations also including a set of industry, year and country dummies as controls).

By construction, our dynamic equation suffers from endogeneity due to the presence of the lagged dependent variable in the model. However, endogeneity problems may also arise from other covariates in the model (for instance, it may well be the case that wage and employment decisions are jointly and simultaneously adopted, as well as the output and investment decisions can be jointly affected by a temporary shock). Hence, all the explanatory variables have been cautiously considered as potentially endogenous to labor

\footnotetext{
${ }^{13}$ An alternative approach for estimating dynamic panel models is the difference GMM, developed by Arellano and Bond (1991). We favour the system GMM estimator since the difference GMM estimator has been proved to be strictly dominated by GMM-SYS when (1) there is strong persistence in the time series (as in our case, with a $\rho=0.994$, see Table A2.1) and/or (2) the time dimension and time variability of the panel is small compared with its cross-section dimension and variability, as it is the case in our database (see Bond et al., 2001).
} 
demand and instrumented when necessary. The level of lagged instruments has been chosen in order to reject the null hypothesis of no autocorrelation. We used thrice lagged instruments for most of the models. ${ }^{14}$

\section{Empirical results}

The results from the GMM-SYS estimation of equation (3) using the full sample - 19,978 European firms originating from 104,074 observations - are presented in Table 5. Overall, the model performs well and reveals highly significant coefficients with the expected signs. The positive and highly significant value of the lagged dependent variable confirms pathdependency and persistence in labor demand. The magnitude of this coefficient (0.67) as well as the estimates of the other standard determinants of labor demand, i.e. value added $(0.30)$ and gross investments (0.13) are in line with prior studies (see Section 2). Finally, the estimated effect of the labor cost per employee on labor demand is negative as expected.

Turning our attention to the main variable of interest, the estimate shows a positive but not significant effect of simple normalized patent counts over employment. Interestingly enough, moving to our more reliable indicator, the coefficient of citation-weighted patent counts becomes significant at a 95\% level. This effect is far from being negligible: if a firm increases its innovative effort and doubles its number of patents (weighted by forward citations), the expected increase in employment amounts to $5 \%$.

As far as the diagnostic tests are concerned, both the Wald test on the overall significance of the regression and the LM tests on the AR(1), AR(2) and AR(3) dynamics are fully reassuring. Instead, the null of adequate instruments is rejected by the Hansen test. However, since it has been shown that the Hansen test over-rejects the null in case of very large samples (Blundell and Bond, 2000; Roodman, 2006), the same model was run and the Hansen test performed on different random sub-samples comprising $10 \%$ of the original data; in all the cases, the null was never rejected, providing reassurance on the validity of the chosen instruments. ${ }^{15}$

\footnotetext{
${ }^{14}$ Twice lagged instruments were sufficient to reject auto-correlation for the estimations on high-tech and lowtech manufacturing (see Table 7) as well as for the estimations without Italy (see Appendix 2, Table A2.2).

${ }^{15}$ Results available from the authors upon request.
} 
Table 5: Results from GMM-SYS analysis

\begin{tabular}{lll}
\hline & Employment & Employment \\
\hline Employment ${ }_{\mathrm{t}-1}$ & $0.673^{* * *}$ & $0.670^{* * *}$ \\
Value added & $(0.016)$ & $(0.016)$ \\
& $0.301^{* * *}$ & $0.302^{* * *}$ \\
Patents & $(0.015)$ & $(0.015)$ \\
& 0.051 & \\
Weighted patents & $(0.040)$ & \\
& & $0.050^{* *}$ \\
Gross investments & & $(0.021)$ \\
& $0.135^{* * *}$ & $0.131^{* * *}$ \\
Labor cost per employee & $(0.037)$ & $(0.037)$ \\
& $-0.287^{* * *}$ & $-0.304^{* * *}$ \\
Constant & $(0.095)$ & $(0.096)$ \\
& $0.408^{* * *}$ & $0.425^{* * *}$ \\
Time, industry and country dummies & $(0.059)$ & $(0.060)$ \\
\hline Observations & 104074 & included \\
Number of firms & 19978 & 104074 \\
Wald test & $6290000^{* * *}$ & 19978 \\
AR(1) & $-24.89^{* * *}$ & $6350000^{* * *}$ \\
AR(2) & $2.9 * * *$ & $-24.85^{* * *}$ \\
AR(3) & 0.97 & $3.01^{* * *}$ \\
Hansen test & $537.25^{* * *}$ & 0.78 \\
\hline
\end{tabular}

Note: One-step GMM robust standard errors in parentheses. *, **, *** indicate $10 \%, 5 \%$ and $1 \%$ significance levels. Wald test expressed in million. As the Hansen test over-rejects the null in case of very large samples, we performed random sub-sample tests for $10 \%$ of the original data. For these samples the null of the Hansen test was never rejected.

In order to investigate possible peculiarities in the impact of innovation activity over employment across different sectoral groups, we tested our specification on various subsamples. Table 6 reports the results for the manufacturing and service firms respectively, while results for high-tech and medium-tech manufacturing versus low-tech manufacturing firms are presented in

Table $7 .^{16}$

As far as the labor demand variables are concerned, estimation results for the manufacturing and services subsamples are very similar to those obtained from the full sample, with the exception of the loss of significance for gross investments in manufacturing.

Focusing our attention to the estimates using the preferred weighted indicator, while the positive effect of innovative activity on employment remains highly significant for the

\footnotetext{
${ }^{16}$ We followed the Eurostat classification to aggregate manufacturing industries according to technological intensity at the NACE Rev.2, 2-digit level. This classification - based on Hatzichronoglou (1997) - can be found on the following link: http://ec.europa.eu/eurostat/cache/metadata/Annexes/htec_esms_an3.pdf.
} 
manufacturing subsample, innovation does not seem to play a relevant role in labor demand in the service sectors ${ }^{17}$.

When splitting the samples across high-tech and low-tech manufacturing sectors, we find a significant effect of innovation on labor demand for the former category while no significant evidence is observed for the latter category. These results are strongly consistent with prior literature (see Section 2) and further support the view that the labor-friendly impact of innovation is concentrated in the most advanced economic sectors.

Table 6: Results from GMM-SYS analysis: manufacturing vs services

\begin{tabular}{|c|c|c|c|c|}
\hline \multirow[b]{3}{*}{ Employment $_{\mathrm{t}-1}$} & \multicolumn{4}{|c|}{ Employment } \\
\hline & \multicolumn{2}{|c|}{ Manufacturing } & \multicolumn{2}{|c|}{ Services } \\
\hline & $\begin{array}{l}0.687 * * * \\
(0.015)\end{array}$ & $\begin{array}{l}0.686 * * * \\
(0.015)\end{array}$ & $\begin{array}{l}0.589 * * * \\
(0.030)\end{array}$ & $\begin{array}{l}0.585^{* * * *} \\
(0.030)\end{array}$ \\
\hline Value added & $\begin{array}{l}0.285^{* * * *} \\
(0.014)\end{array}$ & $\begin{array}{l}0.284^{* * *} \\
(0.014)\end{array}$ & $\begin{array}{l}0.397 * * * \\
(0.030)\end{array}$ & $\begin{array}{l}0.399 * * * \\
(0.030)\end{array}$ \\
\hline Patents & $\begin{array}{l}0.045 \\
(0.045)\end{array}$ & & $\begin{array}{l}0.098 \\
(0.091)\end{array}$ & \\
\hline Weighted patents & & $\begin{array}{l}0.048 * * \\
(0.024)\end{array}$ & & $\begin{array}{l}0.058 \\
(0.040)\end{array}$ \\
\hline Gross investments & $\begin{array}{l}0.041 \\
(0.036)\end{array}$ & $\begin{array}{l}0.043 \\
(0.036)\end{array}$ & $\begin{array}{l}0.170 * * * \\
(0.052)\end{array}$ & $\begin{array}{l}0.160 * * * \\
(0.051)\end{array}$ \\
\hline Labor cost per employee & $\begin{array}{l}-0.204^{* *} \\
(0.102)\end{array}$ & $\begin{array}{l}-0.211^{* *} \\
(0.103)\end{array}$ & $\begin{array}{l}-0.826 * * * \\
(0.156)\end{array}$ & $\begin{array}{l}-0.859 * * * \\
(0.152)\end{array}$ \\
\hline Constant & $\begin{array}{l}0.379 * * * \\
(0.062)\end{array}$ & $\begin{array}{l}0.394^{* * *} \\
(0.063)\end{array}$ & $\begin{array}{l}0.595 * * * \\
(0.090)\end{array}$ & $\begin{array}{l}0.619 * * * \\
(0.089)\end{array}$ \\
\hline Time, industry and country dummies & included & included & included & included \\
\hline Observations & 75546 & 75546 & 28528 & 28528 \\
\hline Number of firms & 13841 & 13841 & 6137 & 6137 \\
\hline Wald test & $5020000 * * *$ & $4980000 * * *$ & $318143.53 * * *$ & $329401.22 * * *$ \\
\hline $\operatorname{AR}(1)$ & $-24.57 * * *$ & $-24.52 * * *$ & $-14.89 * * *$ & $-15.18 * * *$ \\
\hline $\operatorname{AR}(2)$ & $2.18^{* *}$ & $2.18^{* *}$ & $1.81^{*}$ & $1.78^{*}$ \\
\hline $\operatorname{AR}(3)$ & 1.08 & 1.09 & 0.45 & 0.44 \\
\hline Hansen test & $419.25 * * *$ & $3373.05^{* * *}$ & $224.04 * * *$ & $225.45 * * *$ \\
\hline
\end{tabular}

Note: One-step GMM robust standard errors in parentheses. *, **, *** indicate $10 \%, 5 \%$ and $1 \%$ significance levels. As the Hansen test over-rejects the null in case of very large samples, we performed random sub-sample tests for $10 \%$ of the original data. For these samples the null of the Hansen test was never rejected.

\footnotetext{
${ }^{17}$ It has to be considered that this result may be due to the fact that services are far less active in patenting and hence our key indicator may fail to fully capture the nature and magnitude of innovation in such sectors.
} 
Table 7: results from GMM-SYS analysis: high-tech vs low-tech manufacturing

\begin{tabular}{|c|c|c|c|c|}
\hline \multirow{4}{*}{ Employment $_{t-1}$} & \multicolumn{4}{|c|}{ Employment } \\
\hline & \multicolumn{2}{|c|}{ High-tech } & \multicolumn{2}{|c|}{ Low-tech } \\
\hline & $0.676 * * *$ & $0.671 * * *$ & $0.692 * * *$ & $0.694 * * *$ \\
\hline & $(0.017)$ & $(0.017)$ & $(0.020)$ & $(0.019)$ \\
\hline \multirow[t]{2}{*}{ Value added } & $0.291^{* * *}$ & $0.293 * * *$ & $0.289 * * *$ & $0.283 * * *$ \\
\hline & $(0.016)$ & $(0.016)$ & $(0.018)$ & $(0.018)$ \\
\hline \multirow[t]{2}{*}{ Patents } & $0.115^{* * *}$ & & -0.015 & \\
\hline & $(0.043)$ & & $(0.079)$ & \\
\hline \multirow[t]{2}{*}{ Weighted patents } & & $0.080 * * *$ & & 0.001 \\
\hline & & $(0.025)$ & & $(0.038)$ \\
\hline \multirow[t]{2}{*}{ Gross investments } & $0.069 * *$ & $0.063^{* *}$ & 0.035 & 0.041 \\
\hline & $(0.030)$ & $(0.030)$ & $(0.036)$ & $(0.036)$ \\
\hline \multirow[t]{2}{*}{ Labor cost per employee } & $-0.375^{* * *}$ & $-0.408^{* * *}$ & $-0.255^{* *}$ & $-0.229 *$ \\
\hline & $(0.113)$ & $(0.113)$ & $(0.130)$ & $(0.130)$ \\
\hline \multirow[t]{2}{*}{ Constant } & $0.477 * * *$ & $0.499 * * *$ & $0.345^{* * *}$ & $0.366 * * *$ \\
\hline & $(0.068)$ & $(0.070)$ & $(0.087)$ & $(0.082)$ \\
\hline Time, industry and country dummies & included & included & included & included \\
\hline Observations & 40059 & 40059 & 35487 & 35487 \\
\hline Number of firms & 7374 & 7374 & 6467 & 6467 \\
\hline Wald test & $2850000 * * *$ & $2820000 * * *$ & $684045.76^{* * *}$ & $669632.64 * * *$ \\
\hline $\mathrm{AR}(1)$ & $-19.11 * * *$ & $-19.18^{* * *}$ & $-17.21 * * *$ & $-17.25 * * *$ \\
\hline $\operatorname{AR}(2)$ & 1.37 & 1.34 & 1.51 & 1.58 \\
\hline Hansen test & $237.19 * * *$ & $413.01 * * *$ & $339.28 * * *$ & $337.66 * * *$ \\
\hline
\end{tabular}

\section{Conclusions}

In this paper we have investigated the impact of innovative activity - proxied by citationweighted patents - on employment, using a system-GMM approach applied to European microdata. Our findings confirm the labor-friendly nature of innovation at the firm level, in line with prior empirical research (see Section 2).

However, our sectoral estimates show that this positive employment impact is statistically significant only in high- and medium-tech manufacturing sectors, while irrelevant in low-tech manufacturing and in services. Therefore, it seems that patented innovations fully display their labor-friendly nature in the new and emerging sectors, characterized by higher technological opportunities, by higher demand elasticity and by a likely dominance of the "welfare effect" over the "substitution effect" (see Section 1). 
These outcomes prove that the aim of the EU2020 strategy (European Commission, 2010) - that is to develop an European economy based on knowledge and innovation - points in the right direction also in terms of job creation. Moreover - since our impact variable takes into account the quality of the introduced innovation - for policy makers it is also reassuring to know that the demand for labor may further increase as the quality of innovation increases.

However, translating our findings into actual policy measures call for caution. Firstly, it is important to keep in mind that this study has only tested the labor-friendly nature of patented innovation, while neglecting the possible labor-saving impact of non-patented process innovation (see Section 3.2). Secondly, our citation-weighted patent indicator may be a more sophisticated measure of innovation than sheer patent counts, but it should be noted that patents are imperfect indicators of innovation, particularly for firms in the service sectors. In a future study, it may be therefore interesting to try to investigate the possibility to collect different indicators that are better representative for innovation in services. Thirdly, this study has been conducted on a sample of medium-large IPR-intensive firms; therefore, generalizing our results to more aggregate levels is not straight-forward and must take into consideration possible biases in our data coverage. 


\section{References}

Antonucci, T., Pianta, M., 2002. Employment Effects of Product and Process Innovation in Europe. International Review of Applied Economics 16, 295-307.

Arellano, M., Bond, S., 1991. Some Tests of Specification for Panel Data: Monte Carlo Evidence and an Application to Employment Equations. The Review of Economic Studies 58, 277-297.

Arundel, A., Kabla, I., 1998. What percentage of innovations are patented? empirical estimates for European firms. Research Policy 27, 127-141.

Blundell, R., Bond, S., 1998. Initial conditions and moment restrictions in dynamic panel data models. Journal of Econometrics 87, 115-143.

Blundell, R., Bond, S., 2000. GMM Estimation with persistent panel data: an application to production functions. Econometric Reviews 19, 321-340.

Bogliacino, F., Pianta, M., 2010. Innovation and Employment: a Reinvestigation using Revised Pavitt classes. Research Policy 39, 799-809.

Bogliacino, F., Piva, M., Vivarelli, M., 2012. R\&D and employment: An application of the LSDVC estimator using European microdata. Economics Letters 116, 56-59.

Bogliacino, F., Vivarelli, M., 2012. The Job Creation Effect of R\&D Expenditures. Australian Economic Papers 51, 96-113.

Bond, S., Hoeffler, A., Temple, J., 2001. GMM Estimation of Empirical Growth Models. Economics Group, Nuffield College, University of Oxford.

Boyer, R., 1988. New technologies and employment in the 1980s: From science and technology to macroeconomic modelling, in: Kregel, J.A., Matzner, E., Roncaglia, A. (Eds.), Barriers to Full Employment. Macmillan, London, pp. 233-268.

Brouwer, E., Kleinknecht, A., Reijnen, J.O.N., 1993. Employment growth and innovation at the firm level. Journal of Evolutionary Economics 3, 153-159.

Brynjolfsson, E., McAfee, A., 2011. Race against the machine : how the digital revolution is accelerating innovation, driving productivity, and irreversibly transforming employment and the economy. Digital Frontier Press, Lexington, Mass.

Brynjolfsson, E., McAfee, A., 2014. The second machine age : work, progress, and prosperity in a time of brilliant technologies, First Edition. ed. W.W.Norton, New York, NY.

Buerger, M., Broekel, T., Coad, A., 2010. Regional Dynamics of Innovation: Investigating the Co-evolution of Patents, Research and Development (R\&D), and Employment. Regional Studies 46, 565-582.

Coad, A., Rao, R., 2011. The firm-level employment effects of innovations in high-tech US manufacturing industries. Journal of Evolutionary Economics 21, 255-283.

Crespi, G., Tacsir, E., 2012. Effects of innovation on employment in Latin America, InterAmerican Development Bank Institutions for Development (IFD) Technical Note. Inter-American Development Bank, Washington, DC, pp. 1-11.

Dosi, G., 1988. Sources, Procedures, and Microeconomic Effects of Innovation. Journal of Economic Literature 26, 1120-1171.

Dosi, G., Nelson, R.R., 2013. The Evolution of Technologies: An Assessment of the State-ofthe-Art. Eurasian Business Review 3, 3-46.

Edquist, C., Hommen, L., McKelvey, M.D., 2001. Innovation and employment: process versus product innovation. E. Elgar, Cheltenham.

Entorf, H., Pohlmeier, W., 1990. Innovation, employment and export activity: evidence from firm-level data, in: J.-P., F., M., I., J.J., L., F., L. (Eds.), Microeconometrics: surveys and Applications. Blackwell, Oxford, pp. 394-415. 
EPO, OHIM, 2013. IPR-intensive industries: contribution to economic performance and employment in the European Union. Industry-Level Analysis Report, September 2013 ed. EPO, OHIM, Munich - Alicante.

European Commission, 2010. Communication from the Commission to the European Parliament, the Council, the European Economic and Social Committee and the Committee of the Regions. Europe 2020 Flagship Initiative Innovation Union, COM(2010) 546 final. European Commission, Brussels.

Evangelista, R., Savona, M., 2003. Innovation, employment and skills in services. Firm and sectoral evidence. Structural Change and Economic Dynamics 14, 449-474.

Evangelista, R., Vezzani, A., 2012. The impact of technological and organizational innovations on employment in European firms. Industrial and Corporate Change 21, 871-899.

Fagerberg, J., Laestadius, S., Martin, B.R., 2015, forthcoming. The Triple Challenge for Europe: Economic Development, Climate Change, and Governance. Oxford University Press, Oxford.

Feldmann, H., 2013. Technological unemployment in industrial countries. Journal of Evolutionary Economics 23, 1099-1126.

Freeman, C., Soete, L., 1987. Technical change and full employment. B. Blackwell, Oxford, UK ; New York, NY, USA.

Greenan, N., Guellec, D., 2000. Technological Innovation and Employment Reallocation. LABOUR 14, 547-590.

Greenhalgh, C., Longland, M., Bosworth, D., 2001. Technological Activity and Employment in a Panel of UK Firms. Scottish Journal of Political Economy 48, 260-282.

Hall, B.H., Jaffe, A., Trajtenberg, M., 2005. Market Value and Patent Citations. The RAND Journal of Economics 36, 16-38.

Hall, B.H., Lotti, F., Mairesse, J., 2008. Employment, innovation, and productivity: evidence from Italian microdata. Industrial and Corporate Change 17, 813-839.

Hall, B.H., Mairesse, J., 1995. Exploring the relationship between R\&D and productivity in French manufacturing firms. Journal of Econometrics 65, 263-293.

Harhoff, D., Scherer, F.M., Vopel, K., 2003. Citations, family size, opposition and the value of patent rights. Research Policy 32, 1343-1363.

Harrison, R., Jaumandreu, J., Mairesse, J., Peters, B., 2008. Does Innovation Stimulate Employment? A Firm-Level Analysis Using Comparable Micro-Data from Four European Countries. National Bureau of Economic Research Working Paper Series No. 14216.

Harrison, R., Jaumandreu, J., Mairesse, J., Peters, B., 2014. Does innovation stimulate employment? A firm-level analysis using comparable micro-data from four European countries. International Journal of Industrial Organization 35, 29-43.

Hatzichronoglou, T., 1997. Revision of the High-Technology Sector and Product Classification. OECD Science, Technology and Industry Working Papers No. 1997/02.

Katsoulacos, Y.S., 1984. Product innovation and employment. European Economic Review 26, 83-108.

Katsoulacos, Y.S., 1986. The Employment Effect of Technical Change: A Theoretical Study of New Technology and the Labour Market. Wheatsheaf, Brighton.

Klette, J., Førre, S.E., 1998. Innovation And Job Creation In A Smallopen EconomyEvidence From Norwegian Manufacturing Plants 1982-92. Economics of Innovation and New Technology 5, 247-272.

Lachenmaier, S., Rottmann, H., 2011. Effects of innovation on employment: A dynamic panel analysis. International Journal of Industrial Organization 29, 210-220. 
Levin, R.C., Klevorick, A.K., Nelson, R.R., Winter, S.G., 1987. Appropriating the Returns from Industrial Research and Development. Brookings Papers on Economic Activity $18,783-832$.

Marx, K., 1961. Capital: A critical analysis of capitalist production. Foreign Languages Publishing House, first edn. 1867, Moscow.

Neary, J.P., 1981. On the Short-Run Effects of Technological Progress. Oxford Economic Papers 33, 224-233.

Nelson, R.R., Winter, S.G., 1982. An evolutionary theory of economic change. Belknap Press of Harvard University Press, Cambridge, Mass.

Pasinetti, L.L., 1981. Structural change and economic growth : a theoretical essay on the dynamics of the wealth of nations. Cambridge University Press, Cambridge.

Peters, B., 2004. Employment Effects of Different Innovation Activities: Microeconometric Evidence. ZEW Discussion Papers no. 0473.

Petit, P., 1995. Employment and technological change, in: Stoneman, P. (Ed.), Handbook of the Economics of Innovation and Technological Change. North Holland, Amsterdam.

Pianta, M., 2005. Innovation and employment, in: Fagerberg, J., Mowery, D.C., Nelson, R.R. (Eds.), The Oxford handbook of innovation. Oxford University Press, Oxford.

Piva, M., Vivarelli, M., 2004. Technological change and employment: some micro evidence from Italy. Applied Economics Letters 11, 373-376.

Piva, M., Vivarelli, M., 2005. Innovation and Employment: Evidence from Italian Microdata. Journal of Economics 86, 65-83.

Ricardo, D., 1951. Principles of Political Economy, in: Saffra, P. (Ed.), The Works and Correspondence of David Ricardo. Cambridge University Press, Cambridge, third edn. 1821.

Roodman, D., 2006. How to Do xtabond2: An Introduction to "Difference" and "System" GMM in Stata. Center for Global Development Working Papers 103.

Say, J.B., 1964. A treatise on political economy; or, The production, distribution \& consumption of wealth. A. M. Kelley, first edn. 1803, New York,.

Sinclair, P.J.N., 1981. When Will Technical Progress Destroy Jobs? Oxford Economic Papers 33, 1-18.

Spiezia, V., Vivarelli, M., 2002. Innovation and employment: A critical survey, in: Greenan, N., L'Horty, Y., Mairesse, J. (Eds.), Productivity, Inequality and the Digital Economy: A Transatlantic Perspective. MIT Press, Cambridge (Mass.), pp. 101-131.

Squicciarini, M., H. Dernis and C. Criscuolo, 2013. Measuring Patent Quality. OECD Science, Technology and Industry Working Papers 2013/03.

Trajtenberg, M., 1990. A Penny for Your Quotes: Patent Citations and the Value of Innovations. The RAND Journal of Economics 21, 172-187.

UNIDO, 2013. Industrial Development Report 2013. Sustaining Employment Growth: The Role of Manufacturing and Structural Change. United Nations Industrial Development Organization, Vienna.

Van Reenen, J., 1997. Employment and Technological Innovation: Evidence from U.K. Manufacturing Firms. Journal of Labor Economics 15, 255-284.

Vivarelli, M., 1995. The economics of technology and employment : theory and empirical evidence. Edward Elgar, Aldershot.

Vivarelli, M., 2013. Technology, Employment and Skills: An Interpretative Framework. Eurasian Business Review 3, 66-89.

Vivarelli, M., 2014. Innovation, Employment and Skills in Advanced and Developing Countries: A Survey of Economic Literature. Journal of Economic Issues 48, 123154. 
Waterson, M., Stoneman, P., 1985. Employment, technological diffusion and oligopoly. International Journal of Industrial Organization 3, 327-344.

Zimmermann, K.F., 1991. The employment consequences of technological advance, demand and labor costs in 16 German industries. Empirical Economics 16, 253-266. 


\section{Appendix 1: Data sources, merging and cleaning procedures}

This Appendix describes the main steps taken to compile the firm-level dataset used in this study. This involved (a) merging accounting information from the ORBIS database with the OECD PATSTAT at firm level and matching with sectoral deflator data from Eurostat National Accounts and Structural Business Statistics data (see Figure A1.1); and (b) cleaning the merged dataset by removing firms with missing or unreliable information.

Our merging relied on firm-level harmonization tables developed by the authors of the EPOOHIM (2013) study which used sophisticated algorithms to match company entries with that of patents. We extracted data for 70,549 patenting firms identified by that study. It has to be noticed that, while the focus of the EPO-OHIM study was 2004-2008, we had access to patent data for an extended set of firms over the period 2003-2012. However, the need to refer to the EPO-OHIM identification procedure implied the exclusion of all the firms that have only filed patent in 2003 or over the period 2009-2012. Since both ORBIS and PATSTAT were updated by the time we made our data extraction, we could merge 65,720 firms with patent and economic information; however, we decided to focus on manufacturing and services and so to exclude the construction sector from the analysis, which resulted in an uncleaned dataset of 63,561 firms. The sectoral distribution of these companies is shown in Table A1.1, while their cross-country distribution is shown in Table A1.2. We note that of the companies with information on core NACE activity, the distribution between manufacturing and service sectors was rather balanced (45.2 and 42.3\%, respectively). Within these two groups, patenting firms were more concentrated to a few of the sectors: scientific services (16.2\%), retail trade (11.5\%), machinery (10.2\%) and electronics (7.8\%). Almost a third of the firms in the uncleaned dataset were located in Germany, $16.1 \%$ in Italy, $15.1 \%$ in the United Kingdom and 11.2\% of them in France. 
Figure A1.1 Diagram on database mergers

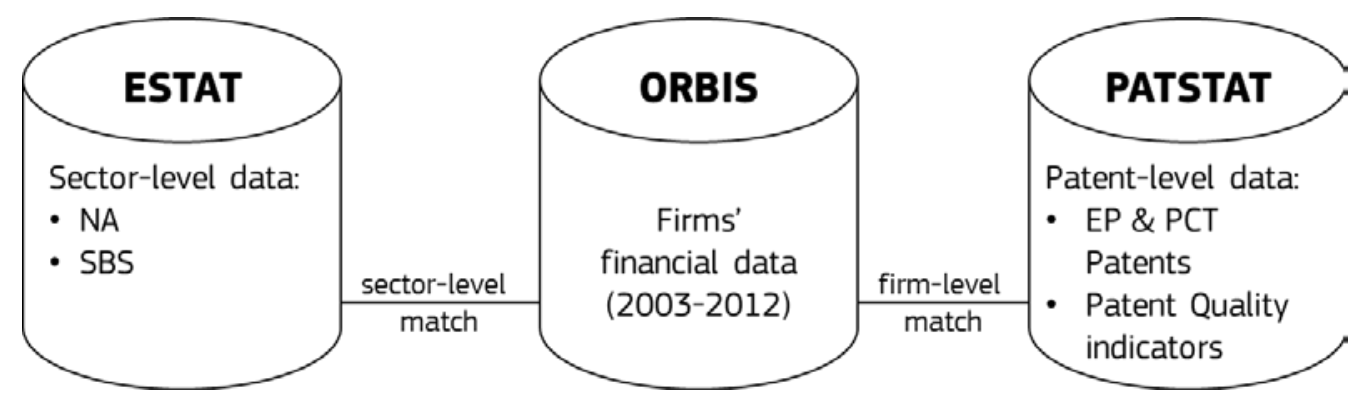

Note: Eurostat (ESTAT) sectoral databases refer to: NA $=$ National Accounts, $\mathrm{SBS}=$ Structural Business Statistics, OECD PATSTAT database refer to: EP = patents filed at the European Patent Office, PCT= patents filed as an international application under the Patent Cooperation Treaty.

Table A1.1: Distribution of firms across sectors before cleaning:

\begin{tabular}{|c|c|c|c|}
\hline & Freq. & Perc. & $\begin{array}{l}\text { Cum. } \\
\text { Perc. }\end{array}$ \\
\hline \multicolumn{4}{|l|}{ Manufacturing } \\
\hline Food & 786 & 1.24 & 1.24 \\
\hline Textile & 1,003 & 1.58 & 2.81 \\
\hline Paper & 1,123 & 1.77 & 4.58 \\
\hline Chemistry & 3,893 & 6.12 & 10.71 \\
\hline Pharmaceutical & 932 & 1.47 & 12.17 \\
\hline Minerals & 971 & 1.53 & 13.70 \\
\hline Metal & 4,314 & 6.79 & 20.49 \\
\hline Electronics & 4,937 & 7.77 & 28.25 \\
\hline Machinery & 6,460 & 10.16 & 38.42 \\
\hline Transport & 1,366 & 2.15 & 40.57 \\
\hline Oth Manufacturing & 2,963 & 4.66 & 45.23 \\
\hline \multicolumn{4}{|l|}{ Services } \\
\hline Electricity/Water & 527 & 0.83 & 46.06 \\
\hline Retail trade & 7,291 & 11.47 & 57.53 \\
\hline Transport Services & 373 & 0.59 & 58.12 \\
\hline Hotel \& Catering & 210 & 0.33 & 58.45 \\
\hline Telecommunication & 2,601 & 4.09 & 62.54 \\
\hline Finance & 1,371 & 2.16 & 64.70 \\
\hline Real Estate & 1,020 & 1.60 & 66.30 \\
\hline Scientific & 10,298 & 16.20 & 82.50 \\
\hline Administration/Education & 2,136 & 3.36 & 85.86 \\
\hline Other services & 1,068 & 1.68 & 87.54 \\
\hline No sector available & 7918 & 19.84 & 100.00 \\
\hline Total & 63,561 & 100.00 & \\
\hline
\end{tabular}


Table A1.2: Distribution of firms across countries before cleaning:

\begin{tabular}{lrrr}
\hline & Freq. & Perc. & Cum. Perc. \\
\hline Austria & 2,211 & 3.48 & 3.48 \\
Belgium & 1,688 & 2.66 & 6.13 \\
Bulgaria & 19 & 0.03 & 6.16 \\
Cyprus & 13 & 0.02 & 6.18 \\
Czech Republic & 242 & 0.38 & 6.57 \\
Denmark & 1,887 & 2.97 & 40.28 \\
Estonia & 64 & 0.10 & 40.38 \\
Finland & 1,682 & 2.65 & 47.29 \\
France & 7,104 & 11.18 & 58.47 \\
Germany & 19,543 & 30.75 & 37.31 \\
Greece & 121 & 0.19 & 58.66 \\
Hungary & 209 & 0.33 & 58.99 \\
Ireland & 1,099 & 1.73 & 60.72 \\
Italy & 10,235 & 16.10 & 76.82 \\
Latvia & 26 & 0.04 & 77.27 \\
Lithuania & 16 & 0.03 & 76.84 \\
Luxembourg & 244 & 0.38 & 77.23 \\
Malta & 1 & 0.00 & 77.27 \\
Netherlands & 128 & 0.20 & 77.47 \\
Poland & 287 & 0.45 & 77.92 \\
Portugal & 181 & 0.28 & 78.21 \\
Romania & 37 & 0.06 & 78.27 \\
Slovakia & 30 & 0.05 & 84.93 \\
Slovenia & 110 & 0.17 & 84.89 \\
Spain & 4,710 & 4.26 & 44.65 \\
Sweden & 9,577 & 6.45 & 84.71 \\
United Kingdom & 15.07 & 100.00 \\
\hline Total & & 100.00 & \\
\hline & & & \\
& 2,561 & & \\
\hline
\end{tabular}

We then followed a similar cleaning process as described in Hall and Mairesse (1995). As a first step, we removed all the firms with either missing or unavailable information (negative values) concerning at least one variable of interest for all the years of the investigated period. This cleaning step removed 37805 firms (almost 60\% of the initial uncleaned merged sample) and was primarily due to the poor quality of the ORBIS data.

The second step in the cleaning process involved the removal of outliers in both levels and growth rates. This step was considered necessary for three reasons: (1) to remove firms with possible erroneous values in the data; (2) to prevent outliers from heavily affecting the results; and (3) to exclude potential biases due to mergers and acquisitions. Concerning level rates, we trimmed the top 1 percentage of the distribution of the overall firms sample for respectively value added per employee, wage cost per employee and fixed assets per employee. As far as growth rates are concerned, we differentiated cut-off levels for various firm sizes to allow larger growth rates for smaller firms. Hence we defined firm sizes as 
micro (0-10 employees), small (11-50 employees), medium (51-250 employees) and large (more than 250 employees). Cut-off values have been defined for one-year growth levels in employees, value added, fixed assets and wage costs. This trimming exercise excluded 2645 firms from the sample (about $4 \%$ of the initial uncleaned sample).

After this cleaning exercise we ended up with a final workable sample of 23,111 firms (about 36\% of the initial one). From this unbalanced panel, 3,133 firms were further dropped by applying our GMM-SYS procedure to the specification (3). 


\section{Appendix 2: Correlation matrix and additional empirical results}

\section{Table A2.1: Correlation matrix}

\begin{tabular}{llccccccc}
\hline \multicolumn{1}{c}{ Variables } & 1 & 2 & 3 & 4 & 5 & 6 & 7 \\
\hline 1 & Employment & 1.000 & & & & & & \\
2 & Employment $t-1$ & 0.994 & 1.000 & & & & & \\
3 & Value added & 0.960 & 0.955 & 1.000 & & & & \\
4 & Weighted patents & 0.312 & 0.310 & 0.326 & 1.000 & & & \\
5 & Patents & 0.278 & 0.277 & 0.290 & 0.925 & 1.000 & & \\
6 & Gross investment & -0.002 & -0.019 & 0.011 & 0.004 & 0.004 & 1.000 & \\
7 & Labor cost per employee & 0.125 & 0.136 & 0.306 & 0.138 & 0.116 & -0.002 & 1.000 \\
\hline
\end{tabular}

Notes: $\mathrm{N}=104,074$ observations. Industry, country and year dummies are omitted due to space limitation.

Table A2.2: Results from GMM-SYS analysis: restricted sample excluding Italian firms

\begin{tabular}{|c|c|c|}
\hline & Employment & Employment \\
\hline \multirow[t]{2}{*}{ Employment $\mathrm{t}_{\mathrm{t}-1}$} & $0.677 * * *$ & $0.669 * * *$ \\
\hline & $(0.018)$ & $(0.018)$ \\
\hline \multirow[t]{2}{*}{ Value added } & $0.286 * * *$ & $0.289 * * *$ \\
\hline & $(0.016)$ & $(0.016)$ \\
\hline \multirow[t]{2}{*}{ Patents } & $0.107^{* *}$ & \\
\hline & $(0.043)$ & \\
\hline \multirow[t]{2}{*}{ Weighted patents } & & $0.083 * * *$ \\
\hline & & $(0.024)$ \\
\hline \multirow[t]{2}{*}{ Gross investments } & $0.098 * * *$ & $0.091 * *$ \\
\hline & $(0.036)$ & $(0.036)$ \\
\hline \multirow[t]{2}{*}{ Labor cost per employee } & $-0.306 * * *$ & $-0.342 * * *$ \\
\hline & $(0.103)$ & $(0.105)$ \\
\hline \multirow[t]{2}{*}{ Constant } & $0.471 * * *$ & $0.516^{* * *}$ \\
\hline & $(0.074)$ & $(0.076)$ \\
\hline Time, industry and country dummies & included & included \\
\hline Observations & 70897 & 70897 \\
\hline Number of firms & 14044 & 14044 \\
\hline Wald test & $35700000 * * *$ & $33700000 * * *$ \\
\hline $\operatorname{AR}(1)$ & $-20.69 * * *$ & $-20.81 * * *$ \\
\hline $\operatorname{AR}(2)$ & 1.16 & 1.10 \\
\hline Hansen test & $334.50 * * *$ & $328.46^{* * *}$ \\
\hline
\end{tabular}

